\section{Parent and teacher report of pragmatic aspects of communication: use of the Children's Communication Checklist in a clinical setting}

\author{
D V M Bishop* MA DPhil, Professor of Developmental \\ Neuropsychology, Department of Experimental Psychology, \\ University of Oxford, Oxford; \\ G Baird Consultant Developmental Paediatrician, Newcomen \\ Centre, Guys Hospital, London, UK. \\ *Correspondence to first author at Department of \\ Experimental Psychology, University of Oxford, South Parks \\ Road, Oxford OX13UD, UK. \\ E-mail: dorothy.bishop@psy.ox.ac.uk
}

The Children's Communication Checklist (CCC) was developed to provide an objective assessment of pragmatic aspects of children's communication difficulties. We aimed to (1) see whether the checklist provided valid and reliable information when completed by parents, and ( 2 ) consider its usefulness in a clinical context. Checklists were completed by parents and a professional who knew the child well for all 5 to $1 \%$-year-old referrals to a tertiary developmental paediatrics centre over a 31-month period. Children who were not yet speaking in sentences were excluded. From a sample of 151 children ( $81 \%$ male; mean age 8.\% years) with pervasive or specific developmental disorders, valid checklists were completed by 119 parents and 93 professionals. Reliability, as measured by internal consistency, was $0.1 \%$ or higher for most scales. Correlations between ratings for parents and professionals were in the range of $\mathbf{0 . 3 0}$ to $\mathbf{0 . 5 8}$ for individual pragmatic scales, with a correlation of $0.46(n=82)$ for the pragmatic composite. For both parents and professionals, the pragmatic composite was lowest for children with a diagnosis of autism; intermediate for those with a diagnosis of Asperger syndrome, pervasive developmental disorder not otherwise specified or attention-deficit-hyperactivity disorder (ADHD); and highest for those with a diagnosis of specific learning disability. The strongest relation between the pragmatic composite and diagnosis was seen when ratings from parents and professionals were combined. Differences between diagnostic groups were not explicable in terms of age or verbal IQ.
Clinicians have a wide range of standardized assessments to choose from when evaluating children's language abilities but most of these focus on language structure, verbal memory, and vocabulary, rather than the use of language in social contexts. For some children, pragmatic impairments present difficulties both to the children and those attempting to communicate with them. This is especially the case for children with high-functioning autism and Asperger syndrome who may have severe disabilities in everyday communication even though scores on traditional language tests can be in the normal range. Problems that have been described in the clinical literature include use of stereotyped language, restriction of conversation to specific topics, difficulties in appreciating non-literal language, and failure to take the perspective of conversational partners into account

There is a clear need for instruments to assess these pragmatic aspects of communication in a more objective fashion but this is not easy to satisfy. Pragmatics may be defined as the appropriate use and interpretation of language in relation to the context in which it occurs (Bishop 1997). Pragmatic competence is, thus, intrinsically dependent on the specific situation in which it is assessed. Bishop (1998) reviewed different approaches to assessment which include standardized assessments using tasks designed to elicit different communicative behaviours, clinical observation in a naturalistic context, and rating scales. One difficulty of relying on clinical observation is that it does not necessarily inform us about pragmatic skills in everyday situations. Furthermore, many of the abnormal communicative behaviours that characterize children with pragmatic impairments are relatively rare in occurrence. For instance, a child may be prone to make overliteral interpretations of utterances but this may occur only once or twice a day. Someone who knows the child well will be able to give numerous examples of such misunderstandings, but it is unlikely that such behaviours will be observed directly in the course of a clinical assessment.

The Children's Communication Checklist (CCC; Bishop 1998; see Appendix) represents a preliminary attempt to address the need for a systematic assessment of the pragmatic aspects of communication. The CCC was developed with the specific goal of distinguishing within the language-impaired population between those children who have pragmatic difficulties and those with more typical forms of specific language impairment (SLI), where the principal problems are with language structure. The checklist was designed to be completed by a professional (teacher or speech and language therapist) who knows the child well. The rater is presented with a statement for each item and has to check whether this 'definitely applies', 'applies somewhat', or 'does not apply'. The rater is also given the option of checking 'unable to judge' but is discouraged from using this response unless there has been no opportunity to observe the behaviour in question. The majority of items are based on clinical descriptions of a subtype of specific language impairment known as semanticpragmatic disorder (Bishop et al. 1983). Five scales, assessing inappropriate initiation, coherence, stereotyped language, use of context, and rapport are included and are combined to give a pragmatic composite. In addition, one set of items assessing aspects of speech production and another assessing syntactic complexity are included to provide information about intelligibility and complexity of expressive speech and language. To give an indication of how far non-language 
autistic features cluster with pragmatic impairments, two further sets of items, assessing social relationships and interests, are also included.

Reliability and validity of the CCC were assessed in a study in which ratings were obtained for 7-year-old pupils $(n=76)$ attending language units in the UK (i.e. special classes for children with SLI; Bishop 1998). For each child, separate ratings were obtained from two professionals who knew the child well, usually a teacher and a speech and language therapist, making it possible to assess interrater reliability. Evidence for validity was obtained from a comparison of three groups of children defined in terms of diagnostic information provided by the school. The SLI-T group were children with typical SLI and no indications of semantic-pragmatic disorder or autistic features; the SP group had a diagnosis of definite or probable semantic-pragmatic disorder but no autistic features; and the group SP+ had a diagnosis of definite or probable semantic-pragmatic disorder and autistic features (though children with a definite diagnosis of autism were excluded). Although there was some overlap between these groups, the pragmatic composite did a reasonable job of discriminating between them, with the SLI-T group obtaining higher scores than the SP group, and the SP group obtaining higher scores than SP+. Furthermore, on the two scales that had been included to assess associated autistic spectrum behaviours in the domains of social relationships and interests, SLI-T and SP groups did not differ whereas the SP+ group did significantly worse.

This initial study suggested that the CCC had promise as a method for identifying pragmatic impairments in children, but clearly further work is needed to assess the validity of the checklist in other contexts. The current study had two major goals. First, we aimed to see whether the CCC could provide valid data if completed by parents rather than teachers. If so, this would make use of the checklist much more feasible in a clinical context, where it may be difficult to obtain information from teachers. Second, we evaluated the usefulness of the CCC for assessing children covering a broader range of ages and diagnoses than in the original study by Bishop (1998), where all children had a primary diagnosis of SLI and were aged between 7 and 8 years at the time the checklist was completed. Because the CCC was originally developed as a tool for subgrouping children with language impairments rather than distinguishing normality from abnormality, data have not previously been gathered on normally developing children. However, if the checklist is to be applied more widely, it would be useful to know what range of scores can be expected for children without impairment. Accordingly, in this study, scores of a clinical sample were compared with those obtained from a normally developing comparison group.

\section{Method}

\section{PARTICIPANTS}

The clinical study population consisted of all new referrals during the periods February 1996 through August 1996 and June 1997 through July 1999 to the Newcomen Centre, London, UK, a tertiary referral centre that specialises in the evaluation of pervasive developmental disorders. After excluding those aged below 5 years or above 17 years $(n=21)$, those with physical disabilities (including hearing loss) or complex syndromes $(n=8)$, children who were not yet speaking in sentences $(n=25)$, those for whom no diagnostic information was available $(n=15)$, and one bilingual child, a pool of 151 children ( $81 \%$ male; mean age 8.7 years) remained. These were diagnosed according to ICD-10 criteria (World Health Organization 1992) and subdivided according to the primary diagnosis into the following groups: (1) autistic disorder (one female, 20 males); (2) Asperger syndrome (three females, 30 males); (3) Pervasive Disorder Not Otherwise Specified (PDDNOS; 10 females, 33 males); (4) attention deficit hyperactivity disorder (ADHD; five females, 19 males); (5) specific learning disability (SLD) including dyslexia and SLI, (seven females, seven males); (6) learning disability (two females, four males), and (7) other (one female, nine males). The Autism Diagnostic Interview - Revised (Lord et al. 1994) was used to diagnose autism and related disorders and the Conners Rating Scale (1969) in conjunction with the Strengths and Difficulties Questionnaire (Goodman 1997) to diagnose ADHD. IQ was assessed in all children using the Kaufman Assessment Battery for Children (1983) or Wechsler Intelligence Scale for Children (Wechsler 1992). Diagnoses of SLI were based on findings from the Clinical Evaluation of Language Fundamentals (Semel et al. 1995). Many children had more than one diagnosis: in this case, they were assigned to the category with the lowest number in the list above. For instance, a child who met diagnostic criteria for both autism and ADHD would be categorized in the autism group. The 'other' group contained a mixture of children with predominantly psychiatric diagnoses such as obsessive-compulsive disorder, conduct disorder, and anxiety separation disorder. Since none of these disorders was common enough to form a separate category, the 'other' group was excluded from the analysis, together with the small group of children with low IQ and no other diagnosis. Thus the pool of potential participants consisted of 135 children in groups (1) to (5).

For a normally-developing comparison group, we gathered CCC data from 31 children aged from 6 to 16 years who had participated as control patients in other studies conducted in our department, and who had been screened to confirm that their verbal and non-verbal abilities were in the normal range and that they were free from any developmental disorders.

PROCEDURE

Parents of children in the clinical sample were sent two copies of the CCC at the time that they received their clinic appointment. They were asked to complete one themselves and to ask the child's teacher, or another professional who had seen the child regularly for at least 3 months, to complete the other. Teachers were asked to place their copy of the CCC in a sealed envelope to avoid parents and teachers influencing one another's responses. For families who were seen in 1996, an extended version of the checklist was used which included an additional 23 items that were subsequently dropped because of low reliability (see Bishop 1998). Parents were requested to bring both copies of the CCC with them to the clinic. For children in the comparison group, a single CCC was completed by teachers for 10 children, and by parents for the remaining 21 children.

Both the extended and final versions of the CCC included a cover sheet in which information was obtained on the child's home language background, any physical disabilities, and type of school attended, as well as the length of time the informant had known the child. 


\section{Results}

DATA FOR CHILDREN IN THE COMPARISON GROUP

Table I shows the mean, SD, and range of scores for the 31 children in the comparison group. All measures are scaled so that a low score indicates impairment and a child who obtained an entirely neutral profile (i.e. no items scored as applying 'somewhat' or 'definitely') would score 30 . Scores greater than 30 are possible for those scales that include positive items that describe communicative strengths; the maximum possible scores for each scale are shown in Table I. It had been anticipated that normally developing children would obtain scores close to the test ceiling and for most scales this was true, with the mean being within 2 points of the scale maximum. Some of the scales and the pragmatic composite showed significant improvement with age.

DATA FOR CHILDREN IN THE CLINICAL SAMPLE

Checklists were obtained from parents for all but eight children in the clinical sample, but a further eight were discarded because fewer than $90 \%$ of items had been completed. This left a total of 119 checklists by parents from the clinical sample. A checklist for a professional (usually a teacher, but in some cases a speech therapist or classroom assistant) was provided for all but 15 children, but for 16 children the respondent had known the child for less than 3 months and so the data were excluded. In a further 11 participants, fewer than $90 \%$ of items had been completed. Thus, valid checklists from professionals were available for 93 children.

RELIABILITY: INTERNAL CONSISTENCY

The Cronbach alpha is a measure of internal consistency that assesses how far the different items in a scale are homogeneous. Alphas for each scale are shown separately for parents and professionals in Table II with the values obtained by Bishop (1998) shown for comparison. In general, the values were not too discrepant with those of the original study, except for the parental ratings of syntax and rapport, and both sets of ratings of interests, all of which were low in the current study. One difference from the original study is that the professionals who rated the children included some teachers in regular mainstream classrooms. In the original study by Bishop (1998) all children were rated by staff working in language units where the staff:pupil ratio is relatively low. To see whether this affected internal consistency we identified those professionals in the current study who worked in specialist settings with small classes or spent time working one-to-one with the child, and contrasted internal consistencies for these raters with the other professionals. Differences between alpha levels were minimal for these two groups.

Table I: Mean (with SD and range) age and CCC scores for children in normally developing comparison group $(n=31)$. Pearson's correlations with age are shown in right column

\begin{tabular}{lrrrrr}
\hline Variable & Scale max & Mean & $S D$ & Range & pwithage \\
\hline Age (y) & - & 9.75 & 3.47 & $6.3-16.7$ & - \\
A. Speech & 38 & 35.13 & 1.52 & $32-37$ & $0.457^{\mathrm{b}}$ \\
B. Syntax & 32 & 31.72 & 0.68 & $30-32$ & 0.218 \\
C. Inappropriate initiation & 30 & 27.16 & 2.11 & $21-30$ & 0.341 \\
D. Coherence & 36 & 35.16 & 1.32 & $31-36$ & 0.280 \\
E. Stereotyped language & 30 & 28.03 & 2.14 & $22-30$ & $0.408^{\mathrm{a}}$ \\
F. Use of context & 32 & 30.48 & 1.88 & $26-33$ & 0.348 \\
G. Rapport & 34 & 32.84 & 1.39 & $30-34$ & -0.065 \\
H. Social relationships & 34 & 32.74 & 1.91 & $26-34$ & -0.203 \\
I. Interests & 34 & 31.54 & 2.11 & $25-34$ & -0.236 \\
Pragmatic composite (scales C-G) & 162 & 153.68 & 6.49 & $140-162$ & $0.389^{\mathrm{a}}$ \\
\hline
\end{tabular}

${ }^{\mathrm{a}} p<0.05$

${ }^{\mathrm{b}} p<0.01$

Table II: Alpha indices of internal consistency for parents and professionals, compared with those obtained with two separate professional groups by Bishop (1998)

\begin{tabular}{lrrr}
\hline Scale & Parent $(n)$ & Professional $(n)$ & Bishop 1998 \\
\hline A. Speech & $0.75(108)$ & $0.8(85)$ & $0.83-0.86$ \\
B. Syntax & $0.54(115)$ & $0.74(93)$ & $0.73-0.78$ \\
C. Inappropriate initiation & $0.77(113)$ & $0.76(83)$ & $0.79-0.80$ \\
D. Coherence & $0.84(107)$ & $0.87(80)$ & $0.84-0.86$ \\
E. Stereotyped language & $0.73(107)$ & $0.82(80)$ & $0.86-0.87$ \\
F. Use of context & $0.72(104)$ & $0.73(77)$ & $0.74-0.84$ \\
G. Rapport & $0.68(104)$ & $0.83(87)$ & 0.87 \\
H. Social relationships & $0.77(84)$ & $0.79(62)$ & $0.8-0.88$ \\
I. Interests & $0.64(101)$ & $0.65(34)$ & $0.73-0.84$ \\
Pragmatic composite (scales C-G) & $0.91(76)$ & $0.92(53)$ & - \\
\hline
\end{tabular}

Alpha computed only for participants with complete data on all items, hence variable $n$. 
RELIABILITY: PARENT-PROFESSIONAL AGREEMENT

A second form of reliability is obtained by considering how far two raters who complete the CCC for the same child agree in their ratings. Valid checklists for both a parent and a professional were available for 82 children in the clinical sample. Pearson's correlations between CCC scales for parent and professional ratings are shown in Table III, with interrater reliability for two professionals from Bishop (1998) shown for comparison. For a sample size of 80 , a correlation of 0.283 is significant at the 0.01 level. Although the correlations between teachers and parents were higher than this, they were generally lower than those observed by Bishop (1998) for two professionals.

To see if agreement was better when computed by staff from specialist settings, we recomputed interrater reliability, using the same subdivision of professionals as made in the internal consistency analysis. Levels of parent-professional agreement were not consistently higher for those professionals who had regular small-group or individual contact with the child compared with the remainder.

RELATION BETWEEN CCC RATINGS AND DIAGNOSTIC CATEGORIES Table IV shows parent CCC ratings in relation to diagnostic category for the clinical sample, and Table V shows corresponding data for professional ratings. Each table also shows the percentage of children in a group who score more than 2 SD below the normal mean, as defined in terms of the data in Table I. The effect of group was tested in separate one-way ANOVAs for each scale. Due to the fact that small sample sizes in some groups give low statistical power, rather than adjusting significance levels for multiple comparisons, the two sets of ratings were compared to see whether findings for parent ratings tended to be replicated with ratings by professionals and whether they agreed with clinical descriptions of the disorders. In comparing Tables IV and V, it is important to note that they are based on overlapping but different subsets of children, so some discrepancies between parents and professionals could reflect inclusion of different children in a group.

Table III: Interrater reliability indices (Pearson's correlations) obtained from current study, compared with those reported by Bishop (1998)

\begin{tabular}{lrr}
\hline Scale & $\begin{array}{r}\text { Parent/Professional } \\
\text { current study } \\
r(n)\end{array}$ & $\begin{array}{r}\text { Twoprofessionals } \\
\text { Bishop (1998) } \\
r(n=71)\end{array}$ \\
\hline A. Speech & $0.58(82)$ & $0.74^{\mathrm{a}}$ \\
B. Syntax & $0.64(76)$ & 0.66 \\
C. Inappropriate initiation & $0.42(81)$ & $0.68^{\mathrm{b}}$ \\
D. Coherence & $0.58(81)$ & 0.62 \\
E. Stereotyped language & $0.35(78)$ & $0.68^{\mathrm{b}}$ \\
F. Use of context & $0.30(80)$ & $0.75^{\mathrm{c}}$ \\
G. Rapport & $0.43(81)$ & $0.83^{\mathrm{c}}$ \\
H. Social relationships & $0.44(68)$ & $0.69^{\mathrm{b}}$ \\
I. Interests & $0.43(55)$ & 0.65 \\
Pragmatic composite & $0.46(82)$ & $0.80^{\mathrm{c}}$ \\
\hline
\end{tabular}

Correlation significantly different in the two studies; ${ }^{\mathrm{a}} p<0.05$;

${ }^{\mathrm{b}} p<0.01 ;{ }^{\mathrm{c}} p<0.001 ;{ }^{\mathrm{d}}$ sum of scales $\mathrm{C}-\mathrm{G}$.

Cases excluded where either rater responded to less than $80 \%$ of items in a scale.
On speech and syntax scales, we would expect the group with SLD to obtain low ratings, and the group with Asperger syndrome to obtain relatively high ratings. This pattern was seen in the professional ratings, although the overall effect of group was not statistically significant. In the parent ratings, the Asperger group did obtain significantly higher syntax ratings than the group with ADHD, though it can be seen from Table IV that the scores of all groups tended to cluster together.

The pattern of results on inappropriate initiation was unexpected. Parents rated the ADHD group as having the lowest score (i.e. the most inappropriate initiation), and this was the only group to differ significantly from the SLD group on this measure. This pattern was not seen for the professional ratings, where most children in all groups scored within normal limits.

Groups did not differ on the coherence scale. With hindsight, this is perhaps not surprising: although the coherence scale forms part of the pragmatic composite, it appears to be heavily dependent on the child's mastery of language structure. Relative to the comparison group, all groups obtained low scores on this scale, which asks about such aspects of communication as the child's ability to tell a story, or to talk about past or future events.

The pattern of scores for stereotyped language was similar for both parents and professionals and significant group differences were seen for both groups of raters, although the group with autism was differentiated from other diagnostic groups only in the professionals' ratings.

Use of context also differentiated groups significantly in both parent and professional ratings but this time it was the parent ratings that gave a significant difference between the groups with autism and SLD.

Parental ratings of rapport gave significant group differences, whereas professional ratings did not. However, scrutiny of the mean scores indicates that for both sets of raters the trend was for the group with autism to obtain the lowest scores, and the SLD group the highest. The Social Relationships scale differentiated between the groups in both sets of ratings, with the SLD group outperforming the group with autism. On Interests, the most striking differences were seen for ratings by professionals, with the Asperger group scoring significantly below the PDDNOS, ADHD, and SLD groups.

Both groups of raters obtained significant differences between groups on the pragmatic composite, with the autism group differing from the SLD group, and the groups with Asperger and PDDNOS and ADHD occupying an intermediate position.

Although the pattern of specific effects on pairwise comparisons differs somewhat between parents and professionals, these are based on slightly different subsets of children, for whom full data were available. To test for significant rater effects, a 3-way ANOVA was conducted using those children who had full data from both raters, with rater and scale as within-participants factors, and diagnosis as a between-participants factor. To avoid small sample sizes arising from missing data on scales $\mathrm{H}$ and I, only scales A to $\mathrm{G}$ were included in this analysis (see Appendix). There were significant main effects of diagnosis, $F(4,64)=3.11, p=0.021$, and of diagnosis $\mathrm{x}$ scale, $F(24,384)=2.42, p<0.001$. The effect of rater was not significant, $F(1,384)=3.32, p=0.073$, nor were the interactions between rater and diagnosis, $F(4,384)=0.88, p=0.481$, or rater 
and scale, $F(6,384)=1.40, p=0.215$. Thus, overall, this analysis supports the conclusion that the different scales are sensitive to the child's diagnosis, but that there are not systematic differences in patterns of ratings between parents and professionals.

Differences between groups were not explicable in terms of age. For parental ratings, the mean (SD) age for the five groups was as follows:autism: 8.04 (1.85), Asperger: 9.49 (3.19), PDDNOS: 8.02 (2.44), ADHD: 8.78 (2.18), SLD: 9.78 (2.42). These means are not significantly different on ANOVA: $F(4,114)=1.39, p=0.243$. Furthermore, within the clinical sample, the Pearson's correlation between the pragmatic composite and age was close to zero $(r=-0.02, n=119)$, and the only significant positive correlations between age and specific scales were for syntax $(r=0.22)$ and coherence $(r=0.18)$, both scales on which the groups did not differ.

The question also arises as to how far the pragmatic composite is related to intellectual ability. In this clinical sample, different IQ tests were used with different children, but data from the Wechsler (1992) scales were available for around half the sample, making it possible to look separately at correlations with Verbal IQ (VIQ) and Performance IQ (PIQ). Neither VIQ nor PIQ was significantly related to the parental pragmatic composite (VIQ: $r_{(56)}=0.182, n s$; PIQ: $\left.r_{(54)}=0.199, n s\right)$. However, the pragmatic composite from professionals was significantly correlated with both VIQ and PIQ (VIQ: $r_{(53)}=0.352, p<0.01$; PIQ: $r_{(51)}=0.417, p<0.01$ ).

Table IV: Parental CCC ratings in relation to diagnostic category

\begin{tabular}{|c|c|c|c|c|c|}
\hline Scale & $\begin{array}{r}\text { Autism } \\
n=17\end{array}$ & $\begin{array}{r}\text { Asperger } \\
n=31\end{array}$ & $\begin{array}{r}P D D N O S \\
n=40\end{array}$ & $\begin{array}{r}A D H D \\
n=22\end{array}$ & $\begin{array}{l}S L D \\
n=9\end{array}$ \\
\hline \multicolumn{6}{|l|}{ A: Speech } \\
\hline Mean & 31.71 & 32.97 & 31.55 & 30.59 & 32.56 \\
\hline SD & 3.80 & 3.33 & 3.69 & 4.78 & 2.46 \\
\hline$\%$ more than 2 SD below normal mean & 53 & 39 & 50 & 59 & 67 \\
\hline \multicolumn{6}{|l|}{ B: Syntax*** } \\
\hline Mean & 30.50 & $31.47^{\mathrm{a}}$ & 30.38 & $30.05^{\mathrm{b}}$ & 30.38 \\
\hline SD & 1.41 & 0.90 & 1.76 & 1.69 & 1.19 \\
\hline$\%$ more than 2 SD below normal mean & 50 & 13 & 48 & 48 & 63 \\
\hline \multicolumn{6}{|l|}{ C: Inappropriate initiation*** } \\
\hline Mean & 22.56 & 24.35 & 24.03 & $22.27^{\mathrm{a}}$ & $26.33^{\mathrm{b}}$ \\
\hline SD & 2.56 & 3.41 & 3.58 & 2.80 & 3.00 \\
\hline$\%$ more than 2 SD below normal mean & 50 & 29 & 41 & 59 & 11 \\
\hline \multicolumn{6}{|l|}{ D: Coherence* } \\
\hline Mean & 25.56 & 29.23 & 28.15 & 28.05 & 27.11 \\
\hline SD & 2.56 & 3.98 & 4.19 & 4.01 & 2.85 \\
\hline$\%$ more than 2 SD below normal mean & 100 & 81 & 82 & 81 & 100 \\
\hline \multicolumn{6}{|l|}{ E: Stereotyped language* } \\
\hline Mean & 20.06 & 22.39 & 22.74 & 22.41 & 24.56 \\
\hline SD & 3.34 & 2.62 & 3.70 & 3.96 & 4.90 \\
\hline$\%$ more than 2 SD below normal mean & 81 & 64 & 54 & 55 & 33 \\
\hline \multicolumn{6}{|l|}{ F: Use of context ${ }^{* *}$} \\
\hline Mean & $21.18^{\mathrm{a}}$ & 23.84 & 23.44 & 22.91 & $26.44^{\mathrm{b}}$ \\
\hline SD & 2.51 & 3.70 & 3.63 & 3.54 & 3.58 \\
\hline$\%$ more than 2 SD below normal mean & 100 & 71 & 82 & 77 & 56 \\
\hline \multicolumn{6}{|l|}{ G: Rapport** } \\
\hline Mean & 25.47 & 25.77 & 27.63 & 28.14 & 28.67 \\
\hline SD & 3.66 & 3.96 & 2.86 & 2.96 & 2.35 \\
\hline$\%$ more than 2 SD below normal mean & 88 & 87 & 85 & 82 & 78 \\
\hline \multicolumn{6}{|l|}{ H: Social relationships* } \\
\hline Mean & $23.36^{\mathrm{a}}$ & 24.77 & 25.49 & 24.81 & $29.00^{\mathrm{b}}$ \\
\hline SD & 4.81 & 3.87 & 4.19 & 4.12 & 4.21 \\
\hline$\%$ more than 2 SD below normal mean & 81 & 80 & 69 & 71 & 44 \\
\hline \multicolumn{6}{|l|}{ I: Interests* } \\
\hline Mean & 27.00 & 27.71 & 29.18 & 28.90 & 29.89 \\
\hline SD & 2.72 & 2.72 & 2.89 & 2.53 & 3.06 \\
\hline$\%$ more than 2 SD below normal mean & 65 & 52 & 23 & 24 & 22 \\
\hline \multicolumn{6}{|l|}{ Pragmatic composite ${ }^{* *}$} \\
\hline Mean & $114.65^{\mathrm{a}}$ & 125.10 & 125.80 & 123.82 & $133.11^{\mathrm{b}}$ \\
\hline SD & 7.39 & 13.00 & 13.02 & 13.26 & 14.02 \\
\hline$\%$ more than 2 SD below normal mean & 100 & 87 & 90 & 86 & 67 \\
\hline
\end{tabular}

$* p<0.05 ; * * p<0.01 ; * * * p<0.001$.

Groups in same row with different superscripts differ significantly at 0.05 level on Scheffé test. Missing data (i.e. where less than $80 \%$ items completed for a scale) for no more than 1 participant per group, except for scale $\mathrm{E}$, where Asperger group has missing data for three children. PDDNOS, pervasive developmental disorder not otherwise specified; ADHD, attention-deficit-hyperactivity disorder; SLD, specific learning disorder. 
Nevertheless, overall, there was a trend for children with a pervasive developmental disorder (autism, Asperger syndrome, or PDDNOS) to have higher VIQ than those with other diagnoses (mean for these three groups $=96.8$, $\mathrm{SD}=23.7, n=36$; mean for other children $=86.1, \mathrm{SD}=18.6$, $n=19)$. It does not appear to be the case, then, that the CCC is merely acting as an alternative way of identifying verbal ability; rather it picks up communicative difficulties that may not be detected on conventional psychometric assessment.

A question of particular interest is how far the pragmatic composite might be useful in discriminating diagnostic groups in clinical practice. Bishop (1998) had suggested that a cut-off of 132 provided best discrimination between children with typical SLI and those with pragmatic language impairments. The proportions of children scoring below this cutoff in relation to clinical group are shown in Table VI. Also shown are the proportions of children who scored below 122, which corresponds to a point that is $2 \mathrm{SD}$ below the mean for Bishop's (1998) sample with typical SLI, and those scoring above 140 , which was the lowest score obtained by a child in the normal comparison group. For parent ratings, the significant association between diagnostic grouping and this categorization approaches statistical significance: $\chi^{2}$ ${ }_{(12)}=20.21, p=0.063$. However, the association was weaker for the professional ratings: $\chi^{2}{ }_{(12)}=14.89, p=0.247$. This differential pattern was not due to the fact that different subsets

Table V: Professional CCC ratings in relation to diagnostic category

\begin{tabular}{|c|c|c|c|c|c|}
\hline Scale & $\begin{array}{r}\text { Autism } \\
n=15\end{array}$ & $\begin{array}{r}\text { Asperger } \\
n=23\end{array}$ & $\begin{array}{r}P D D N O S \\
n=28\end{array}$ & $\begin{array}{r}A D H D \\
n=16\end{array}$ & $\begin{array}{r}S L D \\
n=11\end{array}$ \\
\hline \multicolumn{6}{|l|}{ A: Speech } \\
\hline Mean & 31.47 & 33.04 & 31.36 & 32.25 & 28.64 \\
\hline $\mathrm{SD}$ & 4.10 & 3.04 & 4.00 & 4.71 & 5.03 \\
\hline$\%$ more than 2 SD below normal mean & 47 & 35 & 54 & 50 & 73 \\
\hline \multicolumn{6}{|l|}{ B: Syntax* } \\
\hline Mean & 29.64 & 31.55 & 30.84 & 30.75 & 29.45 \\
\hline $\mathrm{SD}$ & 2.62 & 0.86 & 1.86 & 2.32 & 1.75 \\
\hline$\%$ more than 2 SD below normal mean & 57 & 14 & 28 & 25 & 73 \\
\hline \multicolumn{6}{|l|}{ C: Inappropriate initiation } \\
\hline Mean & 24.79 & 25.48 & 24.93 & 25.38 & 27.45 \\
\hline SD & 3.07 & 2.74 & 3.80 & 2.94 & 2.77 \\
\hline$\%$ more than 2 SD below normal mean & 21 & 17 & 32 & 12 & 0 \\
\hline \multicolumn{6}{|l|}{ D: Coherence* } \\
\hline Mean & 26.33 & 30.43 & 28.78 & 28.25 & 26.80 \\
\hline SD & 3.37 & 3.91 & 4.62 & 5.04 & 3.85 \\
\hline$\%$ more than 2 SD below normal mean & 100 & 65 & 82 & 75 & 100 \\
\hline \multicolumn{6}{|l|}{ E: Stereotyped language*** } \\
\hline Mean & $20.33^{\mathrm{a}}$ & 23.05 & 23.16 & 24.44 & $26.91^{b}$ \\
\hline SD & 4.30 & 3.70 & 4.64 & 3.46 & 2.07 \\
\hline$\%$ more than 2 SD below normal mean & 80 & 41 & 52 & 44 & 0 \\
\hline \multicolumn{6}{|l|}{ F: Use of context* } \\
\hline Mean & 21.73 & 24.43 & 24.37 & 25.13 & 25.82 \\
\hline SD & 2.55 & 3.59 & 4.14 & 3.79 & 4.33 \\
\hline$\%$ more than 2 SD below normal mean & 100 & 78 & 63 & 56 & 46 \\
\hline \multicolumn{6}{|l|}{ G: Rapport } \\
\hline Mean & 24.87 & 26.57 & 27.86 & 27.19 & 28.00 \\
\hline $\mathrm{SD}$ & 3.29 & 3.69 & 3.88 & 5.24 & 3.82 \\
\hline$\%$ more than 2 SD below normal mean & 93 & 87 & 75 & 69 & 73 \\
\hline \multicolumn{6}{|l|}{ H: Social relationships*** } \\
\hline Mean & $23.62^{\mathrm{a}}$ & $24.78^{a}$ & 27.41 & 26.94 & $29.67^{b}$ \\
\hline $\mathrm{SD}$ & 3.40 & 4.32 & 4.10 & 4.04 & 3.00 \\
\hline$\%$ more than 2 SD below normal mean & 90 & 78 & 58 & 63 & 33 \\
\hline \multicolumn{6}{|l|}{ I: Interests*** } \\
\hline Mean & 27.33 & $25.07^{\mathrm{a}}$ & $29.00^{\mathrm{b}}$ & $29.08^{b}$ & $30.80^{\mathrm{b}}$ \\
\hline SD & 1.51 & 3.31 & 3.18 & 3.23 & 1.40 \\
\hline$\%$ more than 2 SD below normal mean & 50 & 80 & 39 & 33 & 0 \\
\hline \multicolumn{6}{|l|}{ Pragmatic composite** } \\
\hline Mean & $118.13^{\mathrm{a}}$ & 129.87 & 129.71 & 130.38 & $135.18^{b}$ \\
\hline $\mathrm{SD}$ & 13.53 & 12.76 & 17.25 & 15.99 & 12.13 \\
\hline$\%$ more than 2 SD below normal mean & 93 & 83 & 71 & 69 & 46 \\
\hline
\end{tabular}

$* p<0.05 ; * * p<0.01 ; * * * p<0.001$.

Groups same row with different superscripts differ significantly at 0.05 level on Scheffé test. Missing data for Social Relationships, Ns are 13, 22, 27, 16, 9; for Interests, Ns are 6, 15, 23, 12, and 10. For all other scales, no more than one missing case per group. PDDNOS, pervasive developmental disorder not otherwise specified; ADHD, attentiondeficit-hyperactivity disorder; SLD, specific learning disorder. 
of children were included in these two analyses; when parent ratings were considered just for the subset of children with ratings by professionals, the association was stronger: $\chi_{(12)}^{2}=23.32, p=0.025$. Thus, although the overall pattern of ratings does not differ between parents and professionals, this categorical analysis suggests that the ratings of parents are more tightly linked to the child's diagnosis. The numbers of children in different diagnostic groups with full ratings by both parents and professionals were small (see Table VI), but analysis of their data suggested that combining information from both sources may be the best way forward; Table VI shows that this gives the best agreement between CCC ratings and diagnosis: $\chi_{(12)}^{2}=29.93, p=0.003$. Although there are significant associations between the pragmatic composite level and diagnostic category, it is clear that one could not use this score to assign a diagnosis to a child. For instance, although the majority of children with a diagnosis of autism have a pragmatic composite below 123 , so do many children with Asperger syndrome, PDDNOS, or ADHD. Conversely, no child with autism had a pragmatic composite above 132 , but some with Asperger syndrome or PDDNOS were found with scores as high as $\mathbf{1 4 0}$ or over.

\section{Discussion}

VALIDITY AND RELIABILITY OF PARENTAL RATINGS

Our study showed that it is feasible to gather parental as well as professional ratings of children's pragmatic competence, and that the parental ratings may, indeed, be more valid insofar as they relate to the child's diagnostic status. We found it helpful to have parents complete the checklist before attending the clinic, as it focused their thinking on ways in which communication could be impaired and facilitated the subsequent clinical interview.

Although internal consistency of ratings was reasonable for both parents and professionals (see Table II), interrater reliability was not always so high (see Table III), especially for the scales forming the pragmatic composite, and for the scales assessing social relationships and interests. Poor parent-teacher agreement is a common finding in the field of psychiatric diagnosis, with parent-teacher correlations for ratings of behavioural/emotional problems typically around the level of 0.2 to 0.4 (e.g. Verhulst and Akkerhuis 1989). The reasons for this have been much discussed. It is possible that the behaviours in question are simply too ill-defined to allow for objective assessment, but if this were the case we would not expect to find much relation between CCC scores and clinical diagnoses. The fact that such relations were found suggests that there is some validity to ratings, and that disagreements between raters may in part reflect the fact that communicative abilities are context dependent. This latter interpretation is favoured by the findings that higher parent-teacher correlations were found for scales assessing language structure, which tend not to vary much with context.

PRAGMATIC SKILLS IN CHILDREN WITH ADHD

One surprising result was the finding that for children with $\mathrm{ADHD}$ the overall pragmatic composite on the CCC was as low as for children with Asperger syndrome or PDDNOS. Although pragmatic difficulties have been described in ADHD (e.g. Oram et al. 1999), these are often attributed to executive dysfunction, e.g. failure of inhibition, poor planning, rather than any underlying difficulties in social understanding. Compatible with this view, children with ADHD obtained especially poor scores on the scale measuring inappropriate initiation, but they also showed evidence of impairments comparable to those in the Asperger and PDDNOS groups on the scales assessing stereotyped language, rapport, and social relationships. There are several possible explanations for this pattern of results: first, it could simply reflect poor discriminating power of the CCC. We know the reliability of the instrument is far from perfect, and any summary score from the checklist will have associated measurement error. However, the lack of even a trend for higher scores in the ADHD group compared with the groups with PDDNOS or

Table VI: Numbers $(\%)$ of children in relation to range of pragmatic composite scores

\begin{tabular}{|c|c|c|c|c|c|}
\hline Rater & Autism & Asperger & PDDNOS & $A D H D$ & $S L D$ \\
\hline \multicolumn{6}{|l|}{ Parents } \\
\hline 140 or more & $0(0)$ & $5(16)$ & $5(12)$ & $3(14)$ & $3(33)$ \\
\hline 133 to 139 & $0(0)$ & $8(26)$ & $8(20)$ & $4(18)$ & $2(22)$ \\
\hline 123 to 132 & $3(18)$ & $3(10)$ & $11(28)$ & $4(18)$ & $3(33)$ \\
\hline below 123 & $14(82)$ & $15(48)$ & $16(40)$ & $11(50)$ & $1(11)$ \\
\hline Total & 17 & 31 & 40 & 22 & 9 \\
\hline \multicolumn{6}{|l|}{ Professionals } \\
\hline 140 or more & $1(7)$ & $5(22)$ & $9(32)$ & $5(31)$ & $6(55)$ \\
\hline 133 to 139 & $1(7)$ & $5(22)$ & $3(11)$ & $2(13)$ & $0(0)$ \\
\hline 123 to 132 & $3(20)$ & $7(30)$ & $6(21)$ & $4(25)$ & $2(18)$ \\
\hline below 123 & $10(67)$ & $6(26)$ & $10(36)$ & $5(31)$ & $3(27)$ \\
\hline Total & 15 & 23 & 28 & 16 & 11 \\
\hline \multicolumn{6}{|c|}{ Average of parent/professional } \\
\hline 140 or more & $0(0)$ & $3(14)$ & $6(23)$ & $4(27)$ & $2(29)$ \\
\hline 133 to 139 & $0(0)$ & $2(9)$ & $4(15)$ & $0(0)$ & $3(42)$ \\
\hline 123 to 132 & $1(8)$ & $10(46)$ & $10(39)$ & $5(33)$ & $1(14)$ \\
\hline below 123 & $11(92)$ & $7(33)$ & $6(23)$ & $6(40)$ & $1(14)$ \\
\hline Total & 12 & 22 & 26 & 15 & 7 \\
\hline
\end{tabular}

Numbers in each group vary because some raters are excluded because of missing data; PDDNOS, pervasive developmental disorder not otherwise specified; ADHD, attention deficit disorder; SLD, specific learning disorder. 
Asperger syndrome in either parent or professional ratings suggests measurement error is not the whole explanation. Another possibility is that the sample of children with ADHD is an atypical one. Children attending a tertiary referral centre often have complex difficulties and multiple diagnoses were the rule rather than the exception in the children in our sample. It is possible that a different picture would have been seen had we recruited a sample from a different clinical source or via epidemiological screening. Our results do, however, also suggest a more radical possibility, namely that the division between pervasive and specific developmental disorders is not a sharp one, and there is considerable continuity between disorders that have traditionally been regarded as distinct. This case has been argued for ADHD by Gillberg (1992), who has postulated that there is a continuum of disorders of empathy, with autism at one extreme and ADHD at the other.

PRAGMATIC SKILLS IN CHILDREN WITH SLD

It is noteworthy that although, in general, the SLD group obtained the highest scores on pragmatic scales, nevertheless, more than half of them scored more than 2 SD below the control mean on the pragmatic composite. Bishop (2000) has proposed that many children with communicative difficulties occupy an intermediate position between classic SLI on the one hand, and autistic disorder on the other; their communicative difficulties extend beyond specific problems with language structure to encompass the social use of language, but they do not have such pervasive and severe disorders in other domains to warrant a diagnosis of autism. The sample of children with SLD in this sample is admittedly small, but overall the pattern of results supports this view of continuity between pervasive and specific developmental disorders.

CLINICAL UTILITY OF THE CCC

Although the CCC was originally designed with the aim of providing information about children with language impairments, this study indicates it may be useful in a broader clinical context. We would not wish to imply that the CCC should be used to diagnose pervasive developmental disorders; although there were significant differences between diagnostic groups on some of the CCC scales. However, on the pragmatic composite, the relation was not close enough to use the CCC to assign a specific diagnosis. Furthermore, as noted above, pragmatic deficits can be found in children who do not have a pervasive development disorder. However, the checklist does provide a simple and cost-effective method for obtaining systematic information about pragmatic difficulties from parents and professionals. It allows one to quantify severity of impairment in aspects of communication that are not easy to assess using conventional tests. Furthermore, it may highlight the presence of communicative problems in children for whom language has not been a major concern. We have found that parents find it acceptable with many reporting that they found completion of the checklist an interesting experience. Further, our data suggest that validity is enhanced by combining information from parents and professionals. There is undoubtedly scope for improving the checklist, in particular by removing or rewording items that attract a high rate of missing data or that have poor reliability. Meanwhile, in its current form, the CCC offers a useful supplement to an assessment battery, complementing the information that can be obtained from standardized language tests.
Accepted for publication 8thJune 2001.

\section{Acknowledgements}

We record our thanks to the parents and teachers who participated in this study, the staff at the Newcomen Centre, and Faith Ayre for her careful assistance with data entry. Dorothy Bishop's research is funded by the Wellcome Trust.

\section{References}

Bishop DVM. (1997) Uncommon Understanding: development and disorders of language comprehension in children. Hove, UK: Psychology Press.

- (1998) Development of the Children's Communication Checklist (CCC): a method for assessing qualitative aspects of communicative impairment in children. Journal of Child Psychology and Psychiatry 39: 879-91.

- (2000) Pragmatic language impairment: a correlate of SLI, a distinct subgroup, or part of the autistic continuum? In: Bishop DVM, Leonard LB, editors. Speech and Language Impairments in Children: causes, characteristics, intervention, and outcome. Hove, UK: Psychology Press. p 99-113.

- Rosenbloom L. (1987) Classification of childhood language disorders. In: Yule W, Rutter M, editors. Language Development and Disorders. Clinics in Developmental Medicine Nos 101/102. London: Mac Keith Press.

Conners CK. (1969) A teacher rating scale for use in drug studies with children. American Journal of Psychiatry 126: 884-8.

Gillberg C. (1992) Autism and autistic-like conditions: subclasses among disorders of empathy. Journal of Child Psychology and Psychiatry 33: 813-42.

Goodman R. (1997) The strengths and difficulties questionnaire: a research note. Journal of Child Psychology and Psychiatry 38: 581-6.

Kaufman AS, Kaufman NL. (1983) Kaufman Assessment Battery for Children, Circle Pines, MN: American Guidance Service.

Lord C, Rutter M, LeCouteur A. (1994) Autism Diagnostic InterviewRevised: a revised version of a diagnostic interview for caregivers of individuals with possible pervasive developmental disorders. Journal of Autism and Developmental Disorders 24: 659-85.

Oram J, Fine J, Okamoto C, Tannock R. (1999) Assessing the language of children with attention deficit hyperactivity disorder. American Journal of Speech-Language Pathology 8: 72-80.

Rapin I, Allen D. (1983) Developmental language disorders: nosologic considerations. In: Kirk U, editor. Neuropsychology of Language, Reading, and Spelling. New York: Academic Press. p 155-84.

Semel E, Wiig EH, Secord WH. (1995) Clinical Evaluation of Language Fundamentals-Third Edition. San Antonio, TX: Psychological Corporation.

Verhulst FC, Akkerhuis GW. (1989) Agreement between parents and teachers ratings of behavioral/emotional problems of children aged 4-12. Journal of Child Psychology and Psychiatry 30: 123-36.

Wechsler D. (1992) Wechsler Intelligence Scale for Children - Third UKedition, London: Psychological Corporation.

World Health Organization (1992) The ICD-10 Classification for Mental and Behavioural Disorders: clinical descriptions and diagnostic guidelines. Geneva: World Health Organization.

\section{Appendix: The Children's Communication Checklist ${ }^{1}$}

For each statement, the rater is asked to judge whether the statement DOES NOT APPLY, APPLIES SOMEWHAT, or DEFINITELY APPLIES. The option 'unable to judge' is also given, but raters are discouraged from selecting this unless they have not had the opportunity to observe the behaviour in question. For each scale, the base score is 30. For negative items (shown as -), 2 points are deducted from this total for each item coded DEFINITELY APPLIES, and 1 point is deducted for APPLIES SOMEWHAT. For positive items (shown as +), 2 points are added to the total for DEFINITELY APPLIES and one point is added for APPLIES SOMEWHAT. The pragmatic composite is the sum of scales $C$ to $G$. 
A: Speech

1. + people can understand virtually everything he/she says

2. - people have trouble in understanding much of what he/she says

3. + seldom makes any errors in producing speech sounds

4. - mispronounces one or two speech sounds but is not difficult to understand; e.g. may say 'th' for 's' or ' $w$ ' for ' $r$ '.

5. - production of speech sounds seems immature, like that of a younger child, e.g. says things like, 'tat' for 'cat', or 'chimbley' for 'chimney', or 'bokkle' for 'bottle'

6. - seems unable to produce several sounds; e.g. might have difficulty in saying ' $\mathrm{k}$ ' or ' $\mathrm{s}$ ', so that 'cat' and 'sat' are both pronounced as 'tat'

7. - leaves off beginnings or ends of words, or omits entire syllables (e.g. 'bella' for 'umbrella')

8. - it is much harder to understand when he/she is talking in sentences, rather than just producing single words.

9. + speech is extremely rapid

10. - seems to have difficulty in constructing the whole of what he/she wants to say: makes false starts, and repeats whole words and phrases; e.g., might say 'can I- can I- can- can I have an - have an ice cream?

11. + speech is clearly articulated and fluent

B: Syntax

12. - speech is mostly 2 to 3 word phrases such as 'me got ball' or 'give dolly'

13. + can produce long and complicated sentences such as: 'When we went to the park I had a go on the swings'; 'I saw this man standing on the corner'

14. - tends to leave out words and grammatical endings, producing sentences such as: 'I find two dog'; 'John go there yesterday' 'My grandma cat been ill'

15. - sometimes makes errors on pronouns, e.g. saying 'she' rather than 'he' or vice versa

\section{C: Inappropriate initiation}

16. - talks to anyone and everyone

17. - talks too much

18. - keeps telling people things that they know already

19. - talks to himself/herself in public

20. - talks repetitively about things that no-one is interested in

21. - asks questions although he/she knows the answers

22. - it is sometimes hard to make sense of what he/she is saying because it seems illogical or disconnected

23. + conversation with him/her can be enjoyable and interesting

\section{D: Coherence}

$24 .+$ can give an easy-to-follow account of a past event such as a birthday party or holiday

25 . + can talk clearly about what he/she plans to do in the future (e.g. tomorrow or next week)

26. - would have difficulty in explaining to a younger child how to play a simple game such as 'snap' or 'happy families'

27. - has difficulty in telling a story, or describing what he/she has done, in an orderly sequence of events

28. - uses terms like 'he' or 'it' without making it clear what he/she is talking about

29. - doesn't seem to realise the need to explain what he/she is talking about to someone who doesn't share his/her experiences; for instance, might talk about 'Johnny' without explaining who he is

${ }^{1}$ Printed copies of the checklist are available for purchase. For details see website: http://epwww.psych.ox.ac.uk/oscci/dbhtml/ccc.htm

\section{E: Stereotyped language}

30. - pronounces words in an over-precise manner: accent may sounds rather affected or 'put-on', as if child is mimicking a TV personality rather than talking like those around him/her

31. - makes frequent use of expressions such as 'by the way', 'actually', 'you know what?', 'as a matter of fact', 'well, you know' or 'of course'

32. - will suddenly change the topic of conversation

33. - often turns the conversation to a favourite theme, rather than following what the other person wants to talk about

34. - conversation with him/her tends to go off in unexpected directions

35. - includes over-precise information in his/her talk, e.g. will give the exact time or date of an event, e.g. when asked 'when did you go on holiday' may say ' 13 th July 1995' rather than 'in the summer'

36. - has favourite phrases, sentences or longer sequences which he/she will use a great deal, sometimes in inappropriate situations

37. - sometimes seems to say things that he/she does not fully understand

F: Use of context

38. - tends to repeat back what others have just said

39. - his/her ability to communicate clearly seems to vary a great deal from one situation to another

40. - takes in just one or two words in a sentence, and so often misinterprets what has been said

41. + can understand sarcasm (e.g. will be amused rather than confused when someone says 'isn't it a lovely day!' when it is pouring with rain)

42. - tends to be over-literal, sometimes with (unintentionally) humorous results. For instance, a child who was asked 'Do you find it hard to get up in the morning' replied 'No. You just put one leg out of the bed and then the other and stand up' Another child who was told 'watch your hands' when using scissors, proceeded to stare at his fingers

43. - gets into trouble because he/she doesn't always understand the rules for polite behaviour and is regarded by others as rude or strange

44. - may say things that are tactless or socially inappropriate

45. - treats everyone the same way, regardless of social status: e.g. might talk to the head teacher the same way as to another child

\section{G: Rapport}

46. - ignores conversational overtures from others (e.g. if asked 'what are you making?' just continues working as if nothing had happened)

47. - seldom or never starts up a conversation; does not volunteer information about what has happened

48. - doesn't seem to read facial expressions or tone of voice adequately and may not realise when other people are upset or angry

49. - poor at using facial expression or gestures to convey his/her feelings; he/she may look blank when angry, or smile when anxious

50. + makes good use of gestures to get his/her meaning across

51. - seldom or never looks at the person he/she is talking to: seems to actively avoid eye contact

52. - tends to look away from the person he/she is talking to: seems inattentive or preoccupied

53. + smiles appropriately when talking to people

\section{H. Social relationships}

54. + is popular with other children

55. + has one or two good friends 
56. - tends to be babied, teased, or bullied by other children

57. - is deliberately aggressive to other children

58. - may hurt or upset other children unintentionally

59. - a loner: neglected by other children, but not disliked

60 . - perceived as odd by other children and actively avoided

61. - has difficulty making relations with others because of anxiety

62. - with familiar adults, he/she seems inattentive, distant or preoccupied

63. - overly keen to interact with adults, lacking the inhibition that most children show with strangers

\section{I: Interests}

64. - uses sophisticated or unusual words; e.g. if asked for animal names might say 'aardvark' or 'tapir'

65. - has a large store of factual information: e.g. may know the names of all the capitals of the world, or the names of many varieties of dinosaurs

66. - has one or more over-riding specific interests (e.g. computers, dinosaurs), and will prefer doing activities involving this to anything else

67. + enjoys watching TV programmes intended for children of his/her age

68. - seems to have no interests: prefers to do nothing

$69 .+$ prefers to do things with other children rather than on his/her own

70. - prefers to be with adults rather than other children 